WellBeing International

WBI Studies Repository

2006

\title{
Forty-two Thousand and One Dalmatians: Fads, Social Contagion, and Dog Breed Popularity
}

Harold A. Herzog

Western Carolina University

Follow this and additional works at: https://www.wellbeingintlstudiesrepository.org/acwp_ca

Part of the Animal Studies Commons, Other Anthropology Commons, and the Social Psychology and Interaction Commons

\section{Recommended Citation}

Herzog, H. (2006). Forty-two thousand and one Dalmatians: Fads, social contagion, and dog breed popularity. Society \& Animals, 14(4), 383-397.

This material is brought to you for free and open access by WellBeing International. It has been accepted for inclusion by an authorized administrator of the WBI Studies Repository. For more information, please contact wbisr-info@wellbeingintl.org.

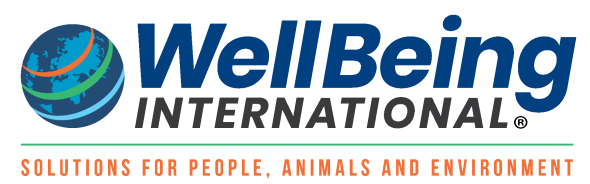




\title{
Forty-two Thousand and One Dalmatians: Fads, Social Contagion, and Dog Breed Popularity
}

\author{
Harold Herzog \\ Western Carolina University
}

\begin{abstract}
Like other cultural variants, tastes in companion animals (pets) can shift rapidly. An analysis of American Kennel Club puppy registrations from 1946 through 2003 ( $N=$ 48,598,233 puppy registrations) identified rapid but transient large-scale increases in the popularity of specific dog breeds. Nine breeds of dogs showed particularly pronounced booms and busts in popularity. On average, the increase (boom) phase in these breeds lasted 14 years, during which time annual new registrations increased 3,200\%. Equally steep decreases in registrations for the breeds immediately followed these jumps in popularity. The existence of extreme fluctuations in preferences for dog breeds has implications for understanding changes in attitudes toward companion animals, veterinary epidemiology, and canine evolution.
\end{abstract}

Like diseases, preferences and behaviors are contagious (Gladwell, 2000; Lynch, 2002; Watts 2003). Examples of large-scale social contagions include such diverse phenomena as changes in baby names (Hahn \& Bentley, 2003; Lieberson, 2000), women's fashions (Richardson \& Kroeber, 1940), sexual behavior (Stoneburner \& Low-Beer, 2004), psychiatric disorders (Acocella, 1999), and suicide rates (Gould, Jamieson, \& Romer, 2003). Although fads in choices for companion animals have been discussed in the anthrozoological literature (Grier, 2006), there are no published quantitative studies of the demographics of rapid cultural changes in pet preferences. Here, based on the analysis of more than 48 million purebred puppy registrations, I show that contagion is a major factor in decisions to acquire purebred dogs.

Founded in 1884, the American Kennel Club (AKC) maintains the world's largest registry of pedigreed dogs. Interest in purebreds grew rapidly in the United States in the years following World War II. Between 1944 and 1972, there was a 20-fold increase in the per capita number of new AKC puppy registrations. Presently, about $60 \%$ of dogs in American homes are considered by their guardians (owners) to be purebreds, though most of these animals are not officially registered (APPMA, 2002). Given the plethora of morphologically diverse breeds, how do people choose a particular type of dog for their canine companion? Factors in the pet selection process include the personality (Podberscek \& Gosling, 2000), social stereotypes (Budge, Spicer, St. George, \& Jones, 1997), and possible matching for physical appearance (Coren, 1999; Roy \& Cristenfeld, 2004). Irvine (2004) offers a perceptive analysis of the selection process in the context of animal shelters.

The AKC provided me with the number of breed registrations dating back to 1946 . This uniquely large and complete data set offers a window into the preferences of Americans for dogs. In two previous reports, my colleagues and I used AKC registrations to examine several aspects of changes in the popularity of dog breeds. In the first (Herzog, Bentley, \& Hahn, 2004), we demonstrated that the neutral model of random drift explains changes in the frequencies of registrations for most breeds of purebred dogs. In the second (Herzog \& Elias, 2004), we found that, contrary to popular belief, winning Best in Show at the Westminster Kennel Club Dog Show does not usually result in a spike in demand for winning breeds.

Note that AKC registrations do not perfectly reflect the likes and dislikes of purebred dog enthusiasts. First, many owners do not submit registration papers. Second, some popular breeds-such as the American pit bull terrier-are not recognized by the AKC, though they may be registered by other kennel clubs. Finally, a few popular breeds have only recently been recognized by the $\mathrm{AKC}$ and, as a result, have misleadingly low registration numbers. For example, the Jack Russell Terrier (referred to as the Parson Russell Terrier by the AKC) was given official AKC recognition in 1998, and the number of their registrations (1,338 in 2005) underestimates the breed's actual popularity. Despite these limitations, AKC registrations provide a well-documented index of the changing tastes of Americans for dogs.

\section{Method}

I obtained from the AKC the number of new registrations for each recognized breed for every year from 1946 (106 breeds) through 2003 (150 breeds) ( $N=48,598,233$ registrations). These numbers were entered into a spreadsheet, 
and population growth graphs were generated for every breed. Over the past 50 years, some breeds have shown little change in popularity (Affenpincers), some have increased steadily (Labrador Retrievers), and others have shown considerable up and down fluctuations (Cocker Spaniels). This report focuses on nine breeds showing pronounced boom-bust patterns of growth and decline: Afghan Hounds, Chow Chows, Dalmatians, Doberman Pinchers, Great Danes, Irish Setters, Old English Sheep Dogs, Rottweilers, and Saint Bernards.

\section{Results}

As is typical of many forms of popular culture, the frequency of AKC registrations conforms to a power law distribution in which a few breeds account for most registrations. Power-law distributions are characteristic of complex systems in which there are mutually interacting parts (Watts, 2003). The distribution of puppy registrations among the available breeds has several characteristic features of power laws. First, the bulk of cases are concentrated among relatively few variants. In 2003, the top 15 breeds accounted for $64 \%$ of new registrations (584,041 dogs). In contrast, the bottom 15 breeds together accounted for only $0.1 \%$ of registrations (1,077 dogs). Second, the tails of power-law distributions are extremely skewed; that is, there are enormous differences between the frequencies of the most popular and least popular variants. In 1967 , there were 30,000 times more poodle registrations $(N=255,862)$ than Clumber Spaniel registrations $(\mathrm{N}=9)$.

Changes in Irish Setter registrations illustrate the demographic pattern that characterizes a dog breed fad. (Figure 1). From the 1940's through the mid 1960's, new Irish Setter registrations hovered between 2,000 and 3,000 a year. In 1962, a tipping point was reached and registrations began to increase at an accelerating rate, a trend which continued for the next 13 years. The annual number of new Irish Setter registrations jumped 25 fold between 1961 and 1974 -from 2,526 to 61,549 . Then, as suddenly as they rose, registrations began to drop; by 1984 , new Irish Setter registrations had fallen to a mere $7 \%$ of what they were a decade earlier. As shown in Figure 2 , when the cumulative number of Irish Setter registrations is plotted as a function of year, the resulting curve shows the classic three stages of epidemics: slow growth, explosive growth, and burn out (Watts, 2003). Figure 3 depicts the growth trends in eight other fad breeds. Summaries of the demographics of all nine breeds are shown in Table 1 . The magnitudes of their swings in popularity are impressive.

Figure 1. Annual number of American Kennel Club registration for new Irish Setters puppies (1946-2003)

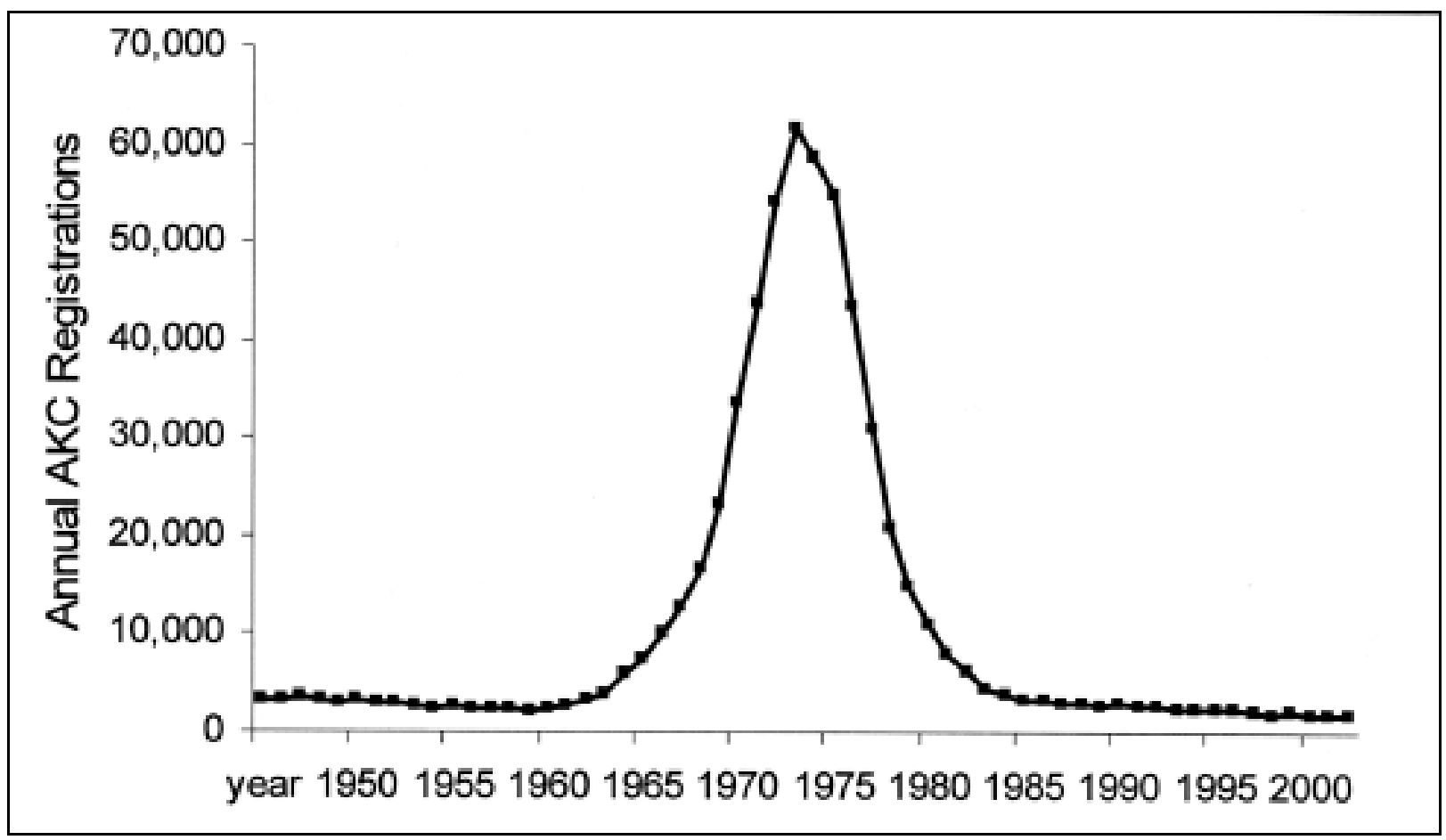


Figure 2. Cumulative number of AKC Irish Setter registrations (1946-2003)

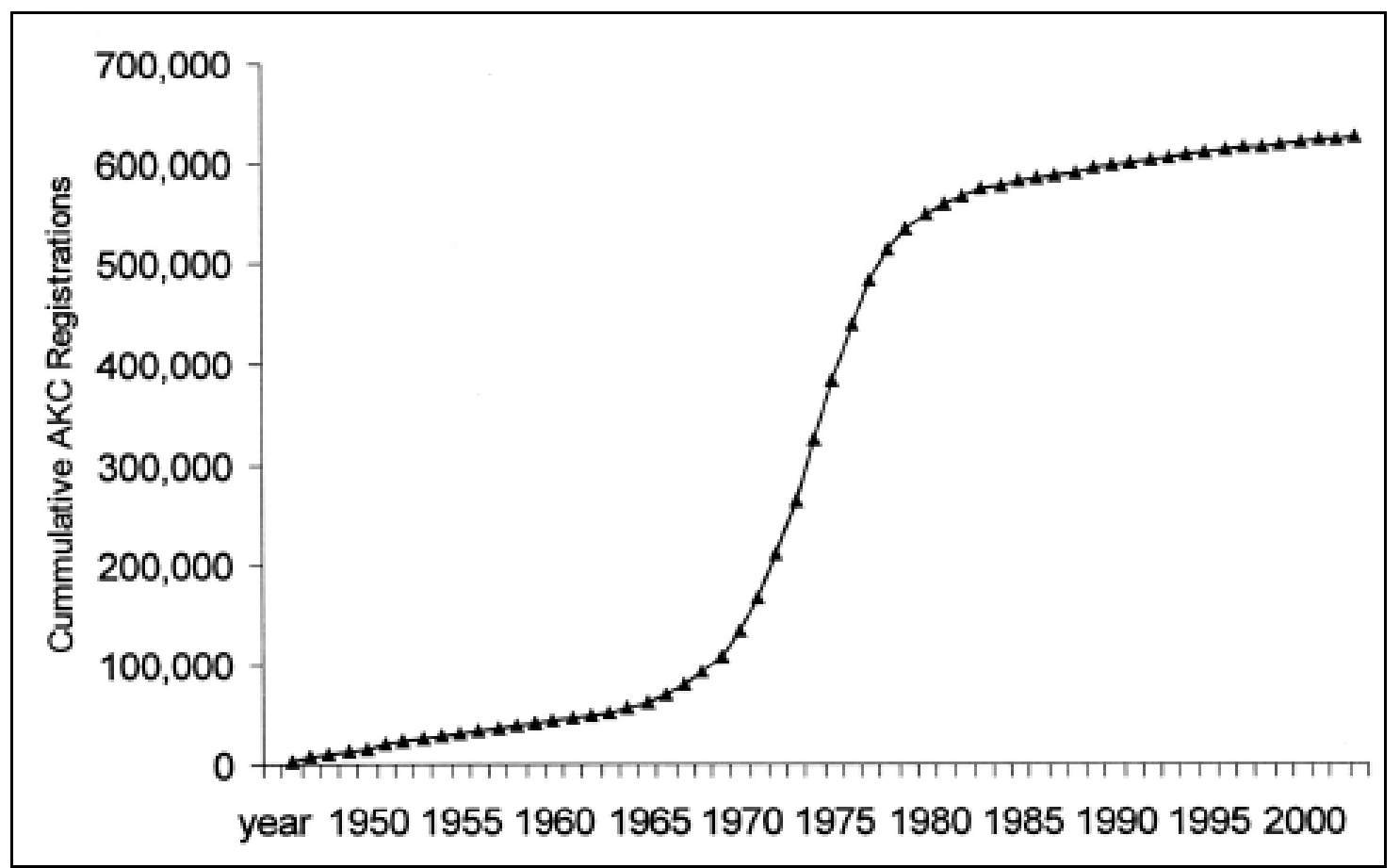

Figure 3. Annual AKC registrations for eight fad dog breeds (1946-2003)

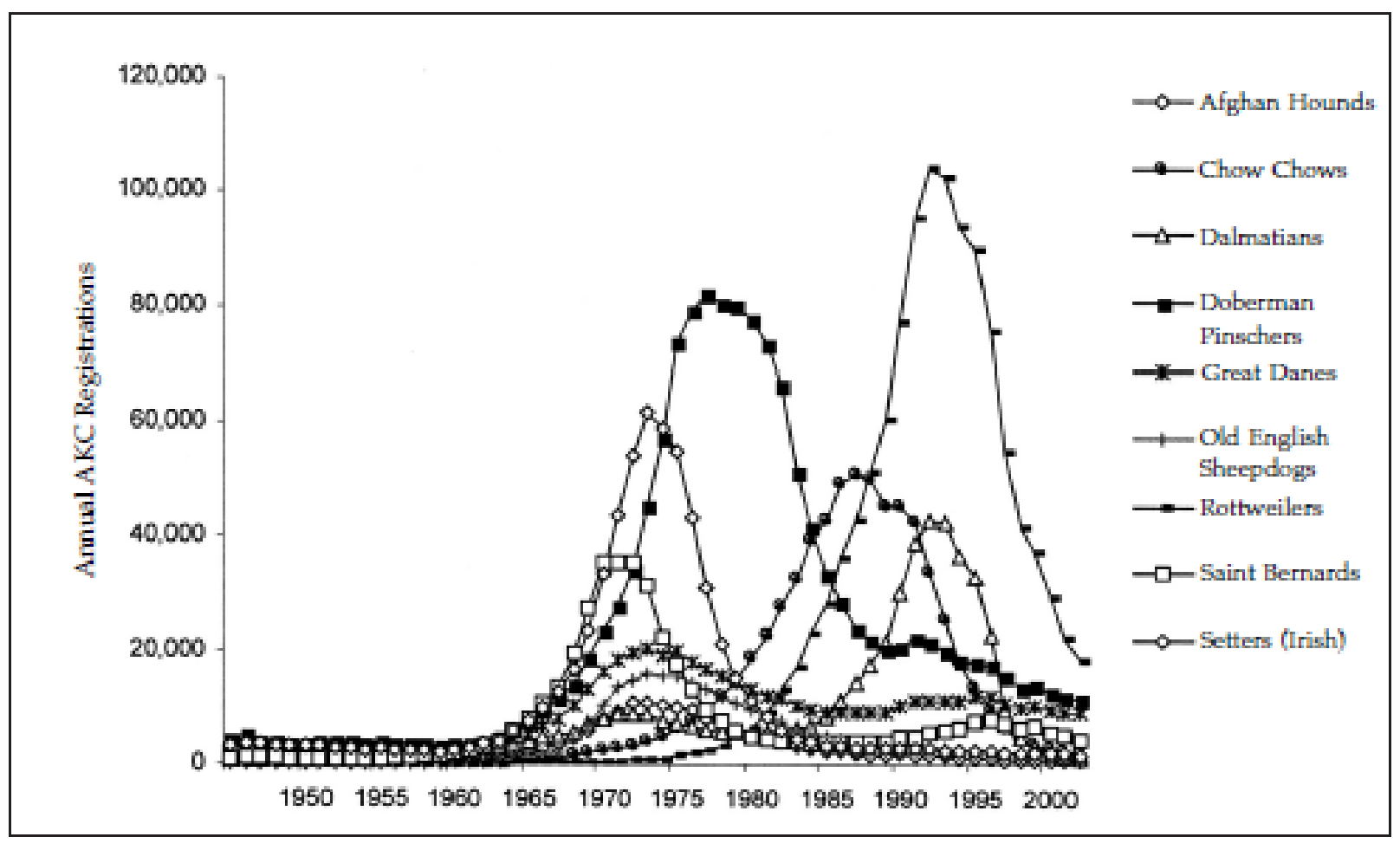


Table 1. Demographic Dimensions of Oscillations in the Number of Annual AKC Registrations of Nine Breeds of Dogs

\begin{tabular}{|c|c|c|c|c|c|c|c|c|c|}
\hline Breed & 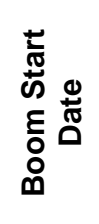 & 总 & 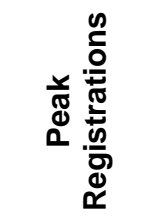 & & 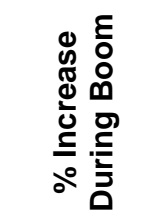 & 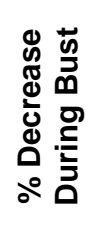 & 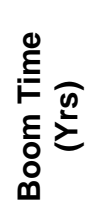 & 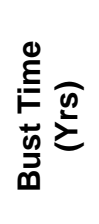 & 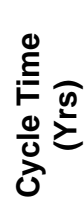 \\
\hline Afghan Hound & 1961 & 831 & 10,918 & 1,690 & $1,314 \%$ & $85 \%$ & 13 & 16 & 29 \\
\hline Chow Chow & 1970 & 1,813 & 50,781 & 2,199 & $2,801 \%$ & $96 \%$ & 18 & 14 & 32 \\
\hline Dalmation & 1983 & 6,032 & 42,816 & 1,112 & $710 \%$ & $97 \%$ & 10 & 10 & 20 \\
\hline Doberman Pincher & 1961 & 3,919 & 81,964 & 20,255 & $2,265 \%$ & $75 \%$ & 17 & 12 & 29 \\
\hline Great Danes & 1963 & 2,839 & 20,319 & 9,145 & $716 \%$ & $55 \%$ & 11 & 12 & 23 \\
\hline Irish Setter & 1961 & 2,526 & 61,549 & 3,179 & $2,437 \%$ & $95 \%$ & 13 & 12 & 25 \\
\hline Old English Sheep Dog & 1960 & 149 & 16,050 & 3,352 & $10,772 \%$ & $79 \%$ & 14 & 16 & 30 \\
\hline Rottweiler & 1976 & 1,406 & 104,160 & 18,216 & $7,408 \%$ & $83 \%$ & 17 & 10 & 27 \\
\hline Saint Bernard & 1961 & 1,867 & 35,559 & 3,797 & $1,905 \%$ & $89 \%$ & 11 & 12 & 23 \\
\hline Mean & & 2,342 & 47,124 & 6,994 & $3,370 \%$ & $84 \%$ & 13.8 & 12.7 & 26.4 \\
\hline SD & & 1,732 & 31,296 & 7,323 & $3,428 \%$ & $13 \%$ & 2.9 & 2.2 & 3.9 \\
\hline
\end{tabular}

During the boom phase, annual registrations in these breeds grew an average of 3,370\% over 13.8 years (range = 10 to 18 years). The most dramatic boom was seen in Old English Sheep Dogs, a breed in which annual registrations increased nearly $11,000 \%$ in 14 years. By the end of their decline, the typical boom/bust breed had only $16 \%$ of the number of annual registrations as at their peak popularity. The bust phases in these breeds lasted, on average, 12.7 years (range $=10$ to 16 years). The average total cycle time from start of the increase phase to the end of the decrease phase was 26.4 years (range $=20$ to 32 years).

Some breeds show booms in popularity but without the precipitous declines characteristic of the boom/bust breeds. Rather, they managed to maintain a reasonably high level of popularity or showed less dramatic drops in popularity. The Poodle, by far the most successful breed in the history of the AKC, is a particularly interesting example. In 1950, Poodles were moderately popular, ranking 16th among recognized breeds with 3,159 new registrations. Then, for reasons that are unclear, Poodle registrations abruptly took off. By 1960, the Poodle was the most popular dog in America. The demand for Poodles peaked in 1969 when the AKC registered 274,154 puppies, an 8,678\% increase in two decades. Poodle registrations fell $50 \%$ over the next six years and continued to decline gradually for two decades. In 2003, Poodles ranked 8th in popularity with 32,176 registrations.

Note that the popularity of purebred dogs may be rapidly declining. New AKC registrations dropped from 1,528,392 in the peak year of 1992 to 921,129 in 2005, a decline of $40 \%$. There are several possible reasons for this drop. These include the availability of alternative registries such as the United Kennel Club and the perception that purebred dogs are particularly susceptible to genetic disorders. In addition, some animal protection organizations have initiated publicity campaigns discouraging ownership of purebred dogs. To counter this trend, the AKC has established programs aimed at recruiting new member from groups of dog owners who have not previously been allied with the organization: for example, raccoon hunters. In addition, the organization established the Canine Health Foundation in 1995 to fund research into causes and treatments of genetic disorders in purebred dogs.

\section{Discussion}

Over the past five decades, shifts in preferences for some types of dogs show the boom-bust patterns that are the hallmarks of fads. Fluctuations of this magnitude suggest that social contagion is a major factor in the choices people make for their animal companions. In this regard, pets are no different from popular music, athletic shoes, and clothing styles. In short, dog breeds have become a form of fashion. This phenomenon is particularly evident in the case of Poodles, where the rise of popularity of the breed in the mid 1950s literally spawned a change in fashion-the ubiquitous poodle skirt.

Not surprisingly, some breed fads are initiated by the media. The best example is the Disney movie 101 Dalmatians. In the eight years following the 1985 re-release of the film, the annual number of new Dalmatian registrations 
increased spectacularly, from 8,170 puppies to 42,816 puppies. The peak in 1993 was followed by the steepest descent in popularity of any breed in AKC history-a decline of $97 \%$ within a decade. An even more dramatic example is the 100-fold increase in Old English Sheepdog registrations over the 14 years following the 1959 Disney movie, The Shaggy Dog.

It is often assumed that fads are inevitably instigated by media exposure. This is not the case. As Lieberson (2000) points out in his study of baby names, it often is impossible to definitively link an increase in the popularity of a cultural variant to a movie or television show. With dogs, there are only a few instances in which there is a clear, causal relationship between a movie and a breed epidemic. The fact is that 101 Dalmatians and The Shaggy Dog are the exceptions rather than the rule. The majority of the many hundreds of movies, television shows, and commercials featuring dogs have had little or no impact on the popularity of obscure breeds. Take the well-known Taco Bell television ad campaign that ran between 1997 and 2000 featuring a Spanish-speaking Chihuahua named Gidget ("Yo quiero Taco Bell"). The extensive exposure of the breed during 3 years of media saturation did not produce an increase in the popularity of Chihuahuas. Indeed, registrations for the breed declined 43\% between 1998 and 2003.

The literature on the psychology, sociology, and economics of fads is extensive, and a review is beyond the scope of this article. However, I will briefly describe perspectives from sociology, anthropology, economics, and evolutionary biology that are, in varying degrees, helpful in understanding booms and busts in dog breed popularity. Note that they are not necessarily mutually exclusive.

\section{Sociology: Lieberson's External and Internal Factors in Cultural Change}

Lieberson (2000) divides the sociological mechanisms that propel rapid changes in public tastes into external and internal factors. External factors are major social, political, and technological trends. An example pertaining to dogs is the post-World War II migration of Americans to suburbs where, for the first time, large numbers of middle-class families lived in homes with dog-friendly yards. Globalization is another external mechanism that has influenced breed popularity. Most AKC registered breeds originated in Europe. Recently, however, China and Japan have emerged as important sources of new types of purebreds. Only $4 \%$ of the 46 breeds recognized by the AKC between 1878 and 1890 were of Asian origin. However, 22\% of the 33 breeds added to the registry between 1942 and 1995 were first developed in Asia (Ray \& Gulley, 1996).

Internal sociological mechanisms can also produce rapid change. Class imitation, for example, is an internal mechanism that occurs when the middle class adopts a cultural variant associated with the rich. As the variant becomes widely popular, tastes of the upper class then shift to a new, more exclusive form. The development of interest in pedigree dogs in Britain and the United States follows this pattern (Grier, 2006; Ritvo, 1987). Increases in the popularity of specific breeds can also result when exclusive dog breeds filter into the mainstream. These include breeds such as Corgies and Lhasa Apsos, originally the province of royalty as well as hunting breeds such as English and Irish Setters, historically associated with the landed gentry.

External and internal mechanisms can interact to produce changes in tastes. Rottweilers showed modest growth during the 1970s but began an explosive increase in popularity in the mid 1980's. In 1983, Rottweilers ranked 25th in popularity $(13,265$ registrations). Ten years later, the Rottweiler was the second most popular breed in the United States with 104,160 annual registrations. A steep bust followed, and registrations declined 83\% over the next decade. One factor in fall of interest in the breed was bad publicity associated with fatal attacks. The number of people killed by Rottweilers in the United States jumped substantially between 1987 and 1998 (Sacks, Sinclair, Gilchrist, Golab, \& Lockwood, 2000). More dogs meant more attacks, which led to a rash of negative news reports and, inevitably, a crash in the demand for puppies. In essence, the breed's decline was a direct consequence of its abrupt rise in popularity.

\section{Anthropology: Cultural Drift (Neutral Theory)}

The simplest model of the transmission of popular culture is to assume that people just copy the behaviors of others. This view is derived from the neutral theory of molecular evolution, which holds that much of evolutionary change is neutral in that it neither enhances nor reduces fitness. The anthropological version is that some cultural variants are analogous to genomic junk DNA; they can increase in popularity via random imitation even though they have no adaptive function (Shennan, 2002). The random drift model has been used to explain popular culture phenomena ranging from baby names to Neolithic pottery styles (Bentley, Hahn, \& Shennan, 2004). Herzog, Bentley, and Hahn (2004) found that a mathematical model based on random drift nicely explains most distributions of AKC puppy registrations among breeds over the past 50 years. 


\section{Economics: Informational Cascades}

Although cultural drift assumes that humans are passive imitators, the informational cascade theory of fads is predicated on the view that people are rational decision-makers (Surowieki, 2004; Watts, 2003). Informational cascades occur when individuals, in the face of uncertainty, opt to follow others rather than making an independent decision (Bikhchandani, Hirshleifer, \& Welch, 1992). One attribute of the informational cascade perspective that makes it particularly applicable to understanding fads is that cascades are fragile; a small amount of additional information can tip the trend to the opposite direction. An example would be a breed that rapidly achieves high levels of popularity but possesses behavioral attributes that make them hard for the average person to live with. The breed could then fall as fast as it rose. (An elegant explanation of informational cascades along with an extensive bibliography is located at http://welch.econ.brown.edu/cascades/.)

\section{Evolutionary Biology: Memes}

In his landmark 1976 book, the biologist Dawkins pointed out the parallels between the mechanisms underlying organic and culture evolution. Dawkins argued that both biological and cultural evolution are the result of differential success of replicators that have the properties of fidelity, fecundity, and longevity. In the case of biological evolution, the replicators are genes. Dawkins named their functional, cultural equivalents memes—bits of cultural information transmitted by imitation. Nursery rhymes, tattoos, and religious beliefs are examples of memes, and computer viruses are a good analogy for them.

Dawkins's idea is controversial. It has attracted legions of enthusiastic converts (Blackmore, 1999; Dennett, 1995) as well as skeptics who argue that the idea provides little real insight into the mechanisms of cultural evolution (Boyd \& Richerson, 2005). Several years ago, I suggested that memes offer a theoretically interesting perspective on why people keep pets (Herzog, 2002). The same logic applies to the rise and fall of the popularity of dog breeds. In this case, memes for the different breeds are spread from mind to mind by imitation, just as a computer virus is spread from machine to machine via the internet. One corollary of the memetic view is that a dog breed could become highly popular even if it made the lives of their owners more difficult.

\section{Why Dog Breed Fads are Important}

There are several reasons why anthrozoologists should be interested in the dynamics of changes in tastes for dogs. First, they demonstrate that human-animal interactions offer systems for the investigation of issues of general interest in the social sciences, in this case, the dynamics of rapid cultural change. Similarly, recent studies of the ability of dogs (but not wolves) to decode human cues such as pointing have shed light on a major issue in cognitive psychology - the evolution of the ability to understand the mental states of others (Hare, Brown, Williamson, \& Tomasello, 2002). Such studies are needed to bring the field of animal studies into the mainstream of the social and behavioral sciences.

Second, canine fads can have health consequences for dogs. Breeds differ in their susceptibility to genetic disorders. I suspect that a boom in a breed's popularity can increase the frequency with which dogs having previously uncommon pathologies show up at veterinary clinics. For example, current interest in toy breeds is likely to be accompanied by an increase in dogs with patellar luxation. Fads may also be a factor in euthanasia of unwanted pets. Individuals who choose a puppy on the basis of unconscious social contagion may find that the now-grown dog is not suited to their living situation. Lifestyle problems are among the most common reasons that owners give for pet relinquishment (Salman et al. 1998), and mismatches between owner and pet may increase the likelihood that a dog's life will end in an animal shelter.

Finally, changes in preferences for dog breeds shed light on the role of human culture on canine evolution. There is controversy over the evolutionary process that led to the emergence of domestic dogs from the grey wolf (Canis lupus). The earliest dog-like fossils date back 14,000 years (Clutton-Brock, 1999). On the other hand, mitochondrial DNA studies, while controversial, suggest a much earlier divergence between dogs and wolves-perhaps as much as 100,000 years ago (Vila, Maldonado, \& Wayne, 1999). The selective breeding of domestic dogs by humans into specialized breeds goes back at least 4,000 years and has resulted in the most morphologically diverse species of mammal on the planet (Clutton-Brock, 1999). However, most of the roughly 400 extant breeds were developed by human agency within the past 200 years (Parker, et al., 2004).

Transient increases in the popularity of dog breeds, coupled with evidence that cultural drift explains overall changes in the distribution of purebred registrations, suggest that at some point in the human-dog relationship there was a shift from function to fashion in domestication processes that produced modern dog breeds (Herzog, Alexander \& Hahn, 2004). Thus, preferences for types of dogs represent a particularly interesting example of culture-gene interactions. In this case, cultural changes in the preferences of one species may have resulted in genetic change in another group 
of animals-dogs. This view is supported by recent evidence that dog domestication was accompanied by a relaxation in selective constraints on the canine genome (Björnerfeldt, Webster, \& Vila, 2006). As a result, there was a substantial increase in the genetic diversity of Canis familiaris, which, in turn, provided the raw, genetic material for the unprecedented morphological and behavioral diversity observed in today's dog breeds.

\section{References}

Acocella, J. (1999). Creating hysteria: Women and multiple personality disorder. San Francisco, Jossey-Bass.

APPMA (2002). 2001-2002 APPM national pet owners survey. Greenwich, CT: American Pet Products Manufacturers Association.

Bikhchandani, S., Hirshleifer, D., \& Welch, I. (1992). A theory of fads, fashion, custom, and cultural change as informational cascades. Journal of Political Economy, 100, 992-1026.

Björnerfeldt, S., Webster, M. T., \& Vila, C. (2006). Relaxation of selective constraint on dog mitochondrial DNA following domestication. Genome Research, DOI: 10.1101/gr.5117706.

Blackmore, S., (1999). The meme machine. New York, NY: Oxford University Press.

Boyd, R., \& Richerson, P. J. (2005). Not by genes alone: How culture transformed human evolution. Chicago: University of Chicago Press.

Budge, R. C., Spicer, J., St. George, R., \& Jones, B. R. (1997). Compatibility stereotypes of people and pets: A photograph matching study. Anthrozoös, 10, 37-46.

Clutton-Brock, J. (1999). A natural history of domesticated mammals. Cambridge: Cambridge University Press.

Coren, S. (1999). Do people look like their dogs? Anthrozoös, 12, 111-114.

Dawkins, R. (1976). The selfish gene. New York: Oxford University Press.

Dennett, D. C. (1995). Darwin's dangerous idea: Evolution and the meanings of life. New York: Simon and Schuster.

Gladwell, M. (2000). The tipping point: How little things can make a big difference. Boston: Little, Brown.

Gould, M., Jamieson, P., \& Romer, D. (2003). Media contagion and suicide among the young. American Behavioral Scientist, 46, 1269-1284.

Grier, K. C. (2006). Pets in America: A history. Chapel Hill: University of North Carolina Press.

Hahn, M. W., \& Bentley, R. A. (2003). Drift as a mechanism for cultural change: An example from baby names. Proceedings of the Royal Society B: Biological Sciences, 270, S120-S123.

Hare, B., Brown, M., Williamson, C., \& Tomasello, M. (2002). The domestication of social cognition in dogs. Science, 298, 1636-1639.

Herzog, H. A., (2002). Darwinism and the study of human-animal interactions. Society and Animals, 4, $316-367$.

Herzog, H. A., Bentley, R. A., \& Hahn, M. W. (2004). Random drift and large shifts in the popularity of dog breeds. Proceedings of the Royal Society B: Biological Sciences, 271, 353-356.

Herzog, H. A., \& Elias, S. M. (2004). The effects of winning the Westminster Kennel Club Dog Show on breed popularity: tests of the Westminster Surge Hypothesis. Journal of the American Veterinary Medical Association, 225, 365-367.

Irvine, L. (2004). If you tame me: Understanding our connection with animals. Philadelphia: Temple University Press.

Lieberson, S. W. (2000). A matter of taste: How names, fashions, and culture change. New Haven: Yale University Press.

Lynch, A. (2002). Evolutionary contagion in mental software. In R. J. Sternberg, \& J. C. Kaufman (Eds.), The evolution of intelligence (pp. 289-314). Mahwah, NJ: Lawrence Erlbaum Associates. 
Parker, H. G., Kim, L. V., Sutter, N. B., Carlson, S., Lorentzen, T. D., \& Malek, T. B. (2004). Genetic structure of the purebred domestic dog. Science, 304, 1160-1164.

Podberscek, A. L., \& Gosling, S. D. (2000). Personality and research on pets and their owners: Conceptual issues and review. In A. L. Podberscek, E. S. Paul, \& J. A. Serpell (Eds.), Companion animals and us: Exploring the relationships between people and pets (pp. 143-167). Cambridge: Cambridge University Press.

Ray, A. G., \& Gulley, H. E. (1996). The place of the dog: AKC breeds in American culture. Journal of Cultural Geography. 16, 89-106.

Richardson, J., \& Krober, A. L. (1940). Three centuries of women's dress fashions: A quantitative analysis. Anthropological Records, 5, 111-153.

Ritvo, H. (1987). The animal estate: The English and other creatures of the Victorian Age. Cambridge: MA: Harvard University Press.

Roy, M. M., \& Christenfeld, N. J. S. (2004). Do dogs resemble their owners? Psychological Science, 15, 361.

Sacks, J. J., Sinclair, L., Gilchrist, J., Golab, G. C., \& Lockwood, R. (2000). Breeds of dogs involved in fatal human attacks in the United States between 1979 and 1988. Journal of the American Veterinary Medical Association, 271, 836-840.

Salman, M. D., New, J. G., Scarlett, J., Kass, P. H., Ruch-Gallie, R., \& Hetts, S. (1998). Human and animal factors related to relinquishment of dogs and cats in 12 selected animal shelters in the United States. Journal of Applied Animal Welfare Science, 1, 207-226.

Shennan, S. (2002). Genes, memes and human history: Darwinian archeology and cultural evolution. London: Thames and Hudson.

Stoneburner, R. L., \& Low-Beer, D. (2004). Population-level HIV declines and behavioral risk avoidance in Uganda. Science, 304, 714-718.

Surowiecki, J. (2004). The wisdom of crowds: Why the many are smarter than the few and how collective wisdom shapes business, economies, societies and nations. New York: Little, Brown.

Vila, C., Maldonado, J. E., \& Wayne, R. K. (1999). Phylogenetic relationships, evolution, and genetic diversity of the domestic dog. Journal of Heredity, 90, 71-77.

Watts, D. J. (2003). Six degrees: The science of a connected age. New York: W. W. Norton. 